\title{
Alman Oryantalizmi ve İslami Dönem Fars Edebiyatı: Bir Literal Geçişkenlik Örneği Olarak Josef von Hammer-Purgstall (1774-1856)
}

\section{German Orientalism and the Persian Literature in the Islamic Period: Josef von Hammer-Purgstall (1774-1856) as an Example of Literary Interlacing}

\author{
Remzi AVCl ${ }^{1}$ (D)
}

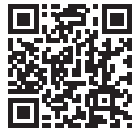

'Dr. Öğretim Üyesi, Mardin Artuklu Üniversitesi, Tarih Bölümü, Artuklu, Mardin, Türkiye

ORCID: R.A. 0000-0002-8539-9203

Corresponding author:

Remzi AVCI,

Mardin Artuklu Üniversitesi, Tarih Bölümü,

Artuklu, Mardin, Türkiye

E-mail: remzavci@gmail.com

Submitted: 07.11.2019

Revision Requested: 29.11.2019

Last Revision Received: 04.12.2019

Accepted: 04.12.2019

Citation: Avci, R. (2019). Alman oryantalizmi ve İslami dönem Fars Edebiyatı: Bir literal geçişkenlik örneğ olarak Josef von Hammer-Purgstall (1774-1856). Alman Dilive Edebiyatı Dergisi - Studien zur deutschen Sprache und Literatur, 42, 57-76.

https://doi.org/10.26650/sds|2019-0017

ÖZ

Avrupa'da İslami dönem Fars dili, kültür ve edebiyatına duyulan ilginin tarihi oldukça eski bir geleneğe dayanmaktadır. Çeviri hareketleri bağlamında düşünüldüğünde İslami dönem Fars edebiyatının Avrupa ile metinsel temasının 17. yüzyılda başladığı söylenebilir. Coğrafya ve kültüre duyulan yakın ilgi seyyahların dil ve edebiyata ilgisini de beraberinde getirmiştir. Bu dönemde birçok Alman seyyah Safevi ülkesine seyahat etmiş ve tarih, kültür, dil ve İslami dönem Fars edebiyat üzerine geniş bilgiler toplayarak bunları Batı'ya aktarmıştır.

1634 yılında Fars edebiyatı klasiklerinden olan Şeyh Sa'dî-i Şîrâzî'nin Gülistan adlı eseri Fransız oryantalist André du Ryer (1580-1660) tarafından Fransızcaya çevrilmiştir. Friedrich Ochsenbach (1606-1658), söz konusu çeviriyi 1636 yılında Fransızcadan Gulistan, das ist, Königlicher Rosengarten/Gülistan, Kraliyet Gül Bahçesi başlığı ile Almancaya çevirmiştir. Safevi ülkesinde medreselerde Farsça öğrenerek Sa'dî'nin eserleri ile tanışmış olan Adam Olearius/Ölschläger (1600-1671), Almanya'ya döndükten sonra Safevi elçisinin yardımıyla Gülistan'ı 1654 yılında Persianische Rosenthal/Fars Güller Vadisi adıyla Almancaya çevirmiştir. 18. yüzyılın sonlarına doğru Avrupa'da Hâfız-ı Şîrâzî ve Şeyh Sa'dî-i Şîẫzî gibi i̇slami dönem Fars şairlerinden Batı dillerine yapılan edebi metin çevirilerdeki artış oryantalistlerden şairlere kadar Almanca konuşulan dünyada da etkisini göstermiştir. Bu zaman dilimi Doğu ve Batı arasında ilişkide bir dönüm noktası olarak düşünülebilir. 19. yüzyılın ise ilk yıllarında diplomat, seyyah, tüccar ve oryantalistlerin yaptıkları çeviriler ile başlayan ve gelişen edebî oryantalizm Almanca konuşulan dünyada Doğu'dan Batı'ya bir Fars şiiri çeviri külliyatı bırakmıştır. Söz konusu külliyatın oluşumunda oldukça önemli bir yerde duran Avusturyalı oryantalist Josef von Hammer-Purgstall (1774-1856), Vinzenz Rosenzweig von Schwannau (1791-1865), Valentin von Huszár (1788-1850), Johann Wolfgang von Goethe (1749-1832), Friedrich Rückert (1788-1866) ve August von Platen (1796-1835) gibi aydınlanmacı, klasik ve romantik akımdan ve birçok düşünür şair ve oryantalistin Fars dili ve şiirine ilgi duymalarında önemli bir etki bırakmıştır. Hammer-Purgstall'ın İslami dönem Fars şiiri çevirilerinden literal bir ağ yarattığını 
iddia eden bu çalışma, onun çevirilerinin Alman edebi oryantalizminin inşa ve kurumsallaşmasında nasıl bir rol oynadığını incelemektedir.

Anahtar Kelimeler: Josef von Hammer-Purgstall, Alman oryantalizmi, Farsça, Hâfız-ı Şîrâzî, Şeyh Sa'dî-i Şîrâzî, çeviri

\section{ABSTRACT (ENGLISH)}

The interest in Persian language, culture and literature in the Islamic period in Europe dates back to a very old tradition. From the point of view of the translation activities, it can be said that the textual contact with the Persian literature in the Islamic Europe began in the 17th century. Due to their strong interest in geography and culture, travelers began to concern themselves with language and literature. During this period, many Germans travelled to the lands of the Safavids. They gathered extensive knowledge about history, culture, language and Persian literature in the Islamic period, and transferred it to the West.

In 1634, the French orientalist André du Ryer (1580-1660) translated into French Sheikh Saadi's Gulistan/The Rose Garden, which is considered to be one of the classics of Persian literature. In 1636, Friedrich Ochsenbach (1606-1658) translated this work from French into German under the title of Gulistan, das ist, Königlicher Rosengarten/Gulistan, Royal Rose Garden. Adam Olearius (Ölschläger 1600-1671), who learned Persian in the Safavid madrasas, became acquainted with the works of Saadi. After his return to Germany, he enlisted the help of the Persian ambassador, and in the year 1654, translated Gulistan into German under the title Persianisches Rosenthal/Valley of the Persian Roses. During the latter part of the 18th century, the increase of translation activities of literary texts of the Persian poets from the Islamic period, such as Hafez Shirazi and Sheikh Saadi-i Shirazi into Western languages in Europe had an impact on German-speaking orientalists and poets. This period can be considered as a turning point in the relationship between Orient and Occident. The early years of the 19th century, literary Orientalism, which began and developed with the translation of diplomats, travelers, traders and orientalists, left a corpus of Persian poetry to the German-speaking world. The Austrian Orientalist Josef von HammerPurgstall (1774-1856) occupies an important place in the formation of this corpus. Hammer-Purgstall's translations made Persian poetry available to classical and romantic thinkers, poets and orientalists. This article has two aims; to show that Hammer-Purgstall created a literal network with his translations from Persian poetry in the Islamic period, and to determine how great a role his translations played in the construction and institutionalization of German literary orientalism.

Keywords: Josef von Hammer-Purgstall, German orientalism, Persian, Hafez Shirazi, Sheikh Saadi Shirazi, translation

\section{EXTENDED ABSTRACT}

All throughout the human history, language, culture and literature have created an intense interaction between civilizations, by crossing the borders of different nations. Therefore, it is possible to see similar cultural elements, which were processed, enriched, and refined in the literary texts of different periods and cultures. From antiquity to the present, the translation activities enabled the transfer of literary texts and served as an intermediary in cultural interaction and transitivity. Philology, more specifically translations from Oriental languages into European languages, can be regarded as one of the important tools that allowed the birth and development of orientalism. Translation, as an intellectual and linguistic activity, constitutes an intercultural interaction and a literary recreation. In the 17th century, the lands of Iran aroused the curiosity of the German-speaking world and caused it to investigate the Persian language and literature. Many Germans traveled to the Safavid dynasty during this period. They gathered 
extensive knowledge about history, culture, language and the Persian literature in the Islamic period, and transferred it to the West. In 1634, French orientalist André du Ryer (1580-1660) translated Sheikh Saadi's Gulistan/The Rose Garden into French, which is to be one of the classics of Persian literature. In 1636, Friedrich Ochsenbach (1606-1658) translated this work from French into German under the title of Gulistan, das ist, Königlicher Rosengarten/Gulistan, Royal Rose Garden. Adam Olearius (Ölschläger 1600-1671), who learned Persian in the Safavid madrasas, became acquainted with the works of Saadi. During the latter part of the 18th century, the increase of translation activities of literary texts of the Persian poets from the Islamic period, such as Hafez Shirazi and Sheikh Saadi-i Shirazi into Western languages in Europe had an impact on German-speaking orientalists and poets. In the 18th century, England and France had the institutionalized colonial administration and trade networks with India, Africa and the Ottoman territories and consequently, a large financial and organizational infrastructure. These potentiality factors made it easier for their citizens to have access to Sanskrit, Persian, Arabic and Hindi manuscripts from Orient, and transfer them to European research centers, libraries and individual scholars. Over time, the philological and literally interest in the Oriental texts increased among scholars and poets. The early years of the 19th century, literary Orientalism, which began and developed with the translation of diplomats, travelers, traders and orientalists, left a corpus of Persian poetry to the German-speaking world. The Austrian Orientalist Josef von Hammer-Purgstall (1774-1856) occupies an important place in the formation of this corpus. Hammer-Purgstall was born in 1774 in the Austrian city of Graz, and studied at the Kaiserlich-königliche Akademie für Orientalische Sprachen/ Imperial Royal Academy for Oriental Languages, a school that educated diplomats in the service of the Habsburg dynasty. After this education, Hammer-Purgstall learned oriental languages such as Persian, Arabic and Turkish, and was sent to Ottoman lands as a diplomat, serving in different units. Between 1809 and 1818, Hammer-Purgstall published a magazine entitled Fundgruben des Orients/The Mines of the Orient in Vienna, which was a pioneering work in the German-speaking world since it differed from the prevailing theological tradition of the time. In 1809, Hammer-Purgstall translated Khosrow and Shirin into German, entitled Schirin, ein morgenlaendisches Gedicht nach morgenländischen Quellen/Shirin, an oriental poem based on oriental sources, which had an important place in Persian literature. He then translated the Divan of Hafez Shirazi into German in its entirety in 1812-1813. Besides his own translation efforts, he contributed to the literal Persian translations by Valentin von Huszár (1788-1850) and Vinzenz Rosenzweig von Schwannau (1791-1865), and published them in his magazine. Although HammerPurgstall's translations of Hafez Shirazi and other Persian texts were pedestrian and not 
very poetic, they had a significant impact on many German poets and orientalists such as Johann Wolfgang von Goethe (1749-1832), Friedrich Rückert (1788-1866) and August von Platen (1796-1835). Rückert, an Orientialist and scholar of oriental languages, introduced the medieval Islamic poetic form known as the ghazel to German poetry. Under the influence of the spirit of Persian poetry, Rückert created a work called Östliche Rosen, and translated from Persian literature in the Islamic period including Mevlana Jalaluddin Rumi, Sheikh Saadi Shirazi and Hafez Shirazi. Hammer-Purgstall's translation of Hafez inspired Goethe as well. He began to write poetry imitating the primary lyrical form, the ghazal of Hafez. For example, Goethe's west-östlicher Divan was influenced by his translations. 


\section{Giriş}

İslami dönem Fars edebiyatının Avrupa ile metinsel temasının 17. yüzyılda başladığı söylenebilir. 1634 yılında Fars edebiyatı klasiklerinden olan Şeyh Sa'dîi-i Şîrâzî'nin Gülistan adlı eserinin tamamı olmasa da bazı kısımları 1647 yılında Kur'an'ı da çeviren Fransız oryantalist André du Ryer (1580-1660) tarafından Gulistan ou l'Empire des Roses/Gülistan'ın Güller Imparatorluğu adıyla Fransızcaya çevrilmiştir (Lewis, 2001).' Bu çalışma, Avrupa'da İslami Dönem Fars edebiyatından yapılan ilk çeviriler arasında yer alır. Edebi Doğu metinleri Almancaya her zaman doğrudan kaynak dilinden kazandırıl(a)mamıştır. Örneğin Friedrich Ochsenbach (1606-1658), yukarıda bahsedilen Ryer'in söz konusu çalışmasını 1636 yılında Fransızcadan Gulistan, das ist, Königlicher Rosengarten/Gülistan, Kraliyet Gül Bahçesi başlı̆̆ı ile Almancaya çevirmiştir (Ochsenbach, 1636). ${ }^{2}$ Bu iki eserin ardından 1644 yılında Hollanda oryantalizminin merkezine dönüşen Protestan Leiden Üniversitesi'nde Doğu dilleri eğitimi alan Alman asıllı oryantalist Levinus Warner (Levino Warnero 16191665) 1644 yılında Sa'dîi'inin Gülistan eserinden bazı kısımları Proverbiorum et Sententiarum Persicarum centuria/Bir Yüzyıl Farsça Atasözleri ve Cümleler adıyla FarsçaLatince olarak yayımlamıştır (1644). Ochsenbach'ın Fransızcadan yaptığı çeviriler ise Hollandalı oryantalist Georg Gentius'un (1618-1687) 1651 yılında Musladini Sadi Rosarium Politicum, Sive Amoenum Sortis Humanae Theatrum adlı Gülistan çevirisine ilham kaynağı olmuştur (Gallien, 2018, s. 27).

Almanya'da ya da coğrafi olarak daha geniş bir ifade ile Almanca konuşulan dünyada söz konusu eserlerin yanısıra İran'a ilginin Ochsenbach'ın çevirisi biryana bırakılırsa 17. yüzyılda seyyahlar aracılığı ile ortaya çıktığı söylenebilir. Coğrafya ve kültüre duyulan yakın ilgi seyyahların dil ve edebiyata ilgisini de beraberinde getirmiştir. Bavyeralı asker Hans Schiltberger'in (1380-1450) uzun yıllar Timur'un sarayında kalması erken dönem Alman seyyahlara bir örnektir. Daha sonra Heinrich von Poser (1599-1661), Adam Olearius (nam-ı diğer Ölschläger 1600-1671), Johann Albrecht von Mandelslo (1616-1644), Engelbert Kaempfer (1651-1716) gibi seyyahlar Safevi ülkesine seyahat etmişler ve 17. yüzyılda tarih, kültür, dil ve edebiyat üzerine geniş bilgiler toplayarak gözlemlerini Batı'ya aktarmışlardır (Schmitt, 2001). Söz konusu seyahat notlarının kitaba dönüşmesi edebi bilginin Batı'ya akışı ve kültür transferinin bir aracı olmuştur. Seyyahların oldukça doğal ve

1 André du Ryer Fransa'nın İskenderiye konsolos vekili olarak da görev yapmıştır (Irwin, 2008, s. 108).

2 Ochsenbach'ın söz konusu çevirisi daha sonra bahsedilecek olan 1846 yılında Moslicheddin Sadi's Rosengarten adıyla teolog oryantalist Karl Friedrich Graf tarafından Almancaya çevrilen Gülistan'ın girişinde "kötü işe yaramaz bir kopya" olarak tasvir" edilmiştir (Graf, 1846). 
abartılı anlatıları daha sonra Batı ve daha özelde Alman kamuoyunda İran kültür ve medeniyeti ile ilgili birikiminin oluşumunda önemli bir farkındalık yaratmıştır.

1637 yılında Safeviler'e elçi olarak gönderilen Adam Olearius, medreselerde mollalardan Farsça öğrenerek Sa'dî'nin eserleri ile tanışmış ve Almanya'ya döndükten sonra Safevi Devleti elçisinin yardımıyla Gülistan'ı 1654 yılında Persianische Rosenthal/Fars Güller Vadisi adıyla Almancaya çevirmiştir (Behzad, 1970, s. 20-22). Olearius, "Alman yurttaşlarına tanıtmaya değer gördüğü ve İran'da da güzel kitapların varlığını kanıtlamış" olduğu bu çalışma ile Almanca konuşulan coğrafyada edebî oryantalizm çalışmaları yapan ilk oryantalistler arasında yer almış, Fars diline ve kültürüne ilgi duyulmasında bir öncü olmuştur (Olearius, 1696, giriş kısmı). Olearius'un Gülistan'ı ana kaynağından, yani Farsçadan Almancaya kazandırması Ochsenbach çevirisine nazaran daha kalıcı bir etki bırakmıştır. Bu örneklerden hareketle Avrupa'da daha özelde Almanya'da İslami dönem Fars edebiyatına merakın uyanmasında seyahat notlarının, tüccar ve elçilerin anlatılarının önemli bir payı olduğu söylenebilir.

İnsanlık tarihi boyunca dil, kültür ve edebiyat farklı milletlerin topraklarında sınırları aşarak medeniyetler arasında ciddi bir etkileşim yaratmıştır. Farklı milletlerin edebi yapıtlarında tamamıyla aynı olmasa da "işlenmiş, zenginleştirilmiş ve arıtılmış" benzer kültür unsurlarını görmek bu transfere somut bir örnek olacaktır (Radjaie, 1998, s. 1). Antikçağdan günümüze kadar edebi metinlerin transferi ancak çeviri ile gerçekleşmiş ve kültürel etkileşim ve geçişkenlikte bir aracı işlevi görmüştür. Filoloji, daha özelde çeviri, oryantalizmin doğuşuna ve gelişimine imkân veren önemli araçlardan biridir. Düşünsel ve dilsel bir faaliyet olan çeviri, "kültürlerarası bir kavşak" olduğu kadar aynı zamanda edebi bir "yeniden yaratmadır". "Çevirmenin etkinliği iki dil, iki kültür, iki çağ iki dönem vb. arasında gidip gelir, kendi varoluş koşullarını yaşarken, varış kültüründeki özünü de yaratır" (Rifat, 2004, s. 9). 19. yüzyılda İslami dönem Fars edebiyatı çevirilerinin Alman klasik ve romantik şiiri üzerinde önemli bir etkisi olmuştur. Bu etki daha sonra bahsedileceği gibi Alman şiir formunda gösterecektir kendini. Diplomat, seyyah, tüccar ve oryantalistlerin yaptıkları çeviriler ile başlayan ve gelişen edebî oryantalizm, Almanca konuşulan dünyada Doğu'dan Batı'ya bir çeviri külliyatı bırakmıştır. Söz konusu külliyatın oluşumunda bu çalışmanın konusu olan Avusturyalı oryantalist Josef von Hammer-Purgstall (1774-1856) çok önemli yerde durmaktadır. Onun çevirileri, Almanca konuşulan dünyada aydınlanmacı, klasik ve romantik akımdan birçok düşünür, şair ve oryantalistin Fars şiirine ilgi duymasında ciddi bir rol oynamıştır (Radjaie, 2018, s. 134). Tarihçi, diplomat, oryantalist, çevirmen, şair gibi farklı kişilikleri olan Hammer- 
Purgstall'ın oryantalist kişiliği ve tarihçiliğini konu edinen oldukça zengin bir literatür vardır..Son yıllarda neredeyse Hammer-Purgstall'ı bütün yönleri ile ele alan mektupları ve terekesindeki diğer malzemelerden binlerce sayfalık kapsamlı bir biyografisi ve binlerce kayıt yayımlandı (Höflechner ve Wagner, 2018)3. Bu oldukça geniş içerikli çalışmanın yanısıra Wilhelm Baum'un (2004) ve Hannas Galter'in (2009) HammerPurgstall'ı modern Alman oryantalizmin öncüsü olarak ele aldığı biyografik makaleleri ise onun Fars edebiyatı ile ilişkisi ve Alman oryantalizmi üzerindeki etkisi bağlamında önemli ipuçları sunmaktadır. Ayrıca Alman şiiri ve Hâfız arasındaki geçişkenlikleri irdeleyen Ali Radjeie (1998) Katharina Mommsen, (1961) Anne Marie Schimmel (2012), Hartmut Bobzin (1989) ve Shafiq Shamel (2007) gibi araştırmacıların HammerPurgstall'ın Alman oryantalizmi ve şiiri üzerindeki etkileri inceleme konusunda önemli bir yerde durdukları söylenebilir. Anne Marie Schimmel'ın A Two-Colored Brocade: The Imagery of Persian Poetry (1992) adlı Fars şiirini incelediği kitabı genel anlamda Fars edebiyatı ve Almanca konuşulan dünyadaki geçişkenliklerle ilgili olarak giriş kısmında önemli bilgiler vermektedir. Her biri kendi alanında bir boşluğu dolduran bu eserlere rağmen Hammer-Purgstall'ın Alman edebi oryantalizminde nasıl bir etki bıraktığı üzerine müstakil bir çalışmanın eksikliği bu makalenin ortaya çıkmasında oldukça etkileyici olmuştur. Özellikle Türkçe literatürde Hammer-Purgstall'ın sadece bir Osmanlı tarihçisi olarak bilinmesi onun edebi kişiliğinin ihmal edilmesinde önemli bir rol oynamaktadır. Hammer-Purgstall'ın İslami dönem Fars edebiyatı çevirileri ile içerisinde Friedrich Rückert (1788-1866), Vinzenz Rosenzweig von Schwannau (1791-1865), Johann Wolfgang von Goethe (1749-1832) ve August von Platen (1796-1835) gibi bazı oryantalist ve şairlerin bulunduğu literal bir ağ ortaya koyduğunu iddia eden bu çalışma, onun çevirilerinin Almanca konuşulan coğrafyada edebi oryantalizmin inşasında nasıl bir rol oynadığını incelemektedir.

Bu makale üç bölümden meydana gelmektedir. Birinci bölüm 18. yüzyılda Avrupa'da çeviriler aracılığı ile klasik dönem Fars edebiyatının nasıl keşfedildiği ve bunun Almanca konuşulan dünyaya nasıl yansıdığını ele almaktadır. İkinci bölüm Hammer-Purgstallın nasıl bir atmosferde Fars edebiyatı ile tanıştığını ve onun İslami dönem Fars şiiri çevirilerini irdelemektedir. Üçüncü bölüm ise Hammer-Purgstall'ın hangi Alman oryantalist ve şairleri etkilediğini ve onun çevirilerinin onlar üzerinde nasıl bir iz bıraktığını ortaya koymayı denemektedir.

3 Söz konusu bu çalışma 2011 yılında Walter Höflechner'in yönetiminde Graz Üniversitesi'nde bir proje şeklinde başlamış ve seri halinde yayımlanmıştır. 


\section{18. Yüzyıl ve Fars Edebiyatının Keşfi}

18. yüzyılda İngiltere ve Fransa'nın Hindistan Afrika ve Osmanlı toprakları ile kurumsallaşmış sömürge ve ticaret ağları ve buna bağlı olarak "büyük finansal ve organizasyonel" altyapının sağladığı imkânlar, Arapça ve Hintçe yazmalarına ulaşımını ve Avrupa'daki kütüphanelere transferini oldukça kolaylaştırmış ve zamanla söz konusu eski metinlere duyulan literal ve filolojik ilginin artmasını sağlamıştır (Polaschegg, 2005, s. 149). 18. yüzyılda Alman oryantalizmi içerisinde İran medeniyetine duyulan ilgi İslami dönem ve İslam öncesi olmak üzere iki ana damardan beslenmiştir. Yukarıda kısa bir giriş yapılan 17. yüzyılda çoğu zaman akademik kaygı taşımayarak çalışılmaya başlanan İslami dönem Fars edebiyatı çevirilerinin yanısıra Fransız oryantalist Abraham Hyacinthe Anquetil-Duperron'un (1731-1805) 1771 yılında bastırabildiği Zerdüştlük dininin kutsal kitabı Avesta çevirisinin Almancaya çevirisi İslam öncesi İran'a ilgi için yeni bir kanal açmıştır. Böylece bir taraftan İslami dönem Fars edebiyatı üzerine çeviriler ve bilimsel çalışmalar yapılırken diğer taraftan da Avesta ve İslam öncesi İran kültürünü merkeze alan bilimsel bir alan doğmuştur. Georg Friedrich Grotefend'in (1775-1853) 1802 yılında antik Pers Krallığı'nın başkenti olan Persepolis'te bulunan Eski Farsça çivi yazılarını çözümlemesi Göttingen Üniversite'sinde İslam öncesi İran çalışmalarının gelişmesine öncülük etmiştir (Schmitt, 2001). Avesta merkezli İslam öncesi İran çalışmaları ve Fars-İslam klasiklerinin yanısıra modern ve arkaik Fars dilleri grameri olmak üzere filoloji merkezli bir alandan da bahsetmek yanlış olmayacaktır. Doğu filolojisinin bir parçası olarak Alman oryantalizmi içerisinde özellikle 1840'lardan itibaren Johann August Vullers (1803-1880) öncülüğünde Almanya'da yer edinmeye çalışan Fars filolojisi tamamen bağımsız bir disiplin olarak üniversitelerde yer edinememiştir. Bunun en temel nedeni Alman oryantalistlerin dil ailelerine olan yaklaşımlarından kaynaklanmıştır. 1850 yılında Sanskritçenin bağımsız bir disiplin olarak ortaya çıkması ile beraber Alman oryantalizmi filoloji araştırmalarında Sami ve Ari, yani Indogermanistik (Hint-Avrupa) olmak üzere iki ana paçaya ayrılmıştır. Alman üniversitelerinde Farsça, bazen Doğu dilleri altında kategorize edilirken bazen de Indogermanistik olarak anılan bölümlerinin Ari kolu altında yer bulmuştur. Fakat Farsça hiçbir zaman Sanskritçenin baskınlığına karşı önemli bir yer edinememiş, hatta onun gölgesinde kalmıştır (Mangold, 2004, s. 102). Almanya'da Fars filolojisi bilimsel olarak özellikle Hint-Avrupa teorisi üzerinden şekillenmiştir. Bunun en temel nedenlerinden birisi Avesta dili çalışmalarında Sanskritçe kelimelere rastlanılarak İran-Hint ilişkisinin kurulmasıyla olmuştur.

18. yüzyılın sonlarında Alman entelektüeller arasında Yunanca ve Latince bilmek ve bu dillerden edebi çeviriler yapmak "ortak bir mülkiyete" dönüşmüştür. 19. yüzyılın başlarında 
ise romantizm akımı ile dünya şiiri düşüncesi oldukça yaygınlaşmış ve Avrupa dilleri dışındaki dillerden çeviriler yapılarak Avrupa şiir formuna uyarlamak moda olmuştur. Hiçbir zaman dini-İslami şiirler klasik antik ya da Roma dönemi şiirleri kadar ilgi görmese de özellikle Doğu'ya edebi ilginin duyulmasında önemli bir yere sahip olan Arap edebiyatından menşei henüz bilinmeyen Bin Bir Gece Masalları'nın farklı Avrupa dillerine çevirileri ve Fars edebiyatından Hâfız-ı Şîrâzî çevirileri oldukça ilgi görmüştür (Wohlleben, 2004 , s. 12$)^{4}$. Fransa ve İngiltere'de Doğu çalışmaları hâkim kolonyal politikadan etkilenerek gelişirken Almanya kendi içerisinde oldukça bağımsız bir gelişmeye sahne olmuştur. Zaten o dönem siyasi birliğini henüz tamamlayamamış olan Almanya'nın dış politikasında benzer bir yapının görülmesi çok mümkün de değildi. Almanya'da edebioryantalizm 19. yüzyılın başında aydınlanma felsefesinin rasyonel düşünce egemenliğine karşı gelişen romantizm akımından etkilenmiştir. "Modern uygarlığa karşı bir itiraz, yaşamın mekanikleştirilip nicelleştirilmesinden, toplumsal ilişkilerin şeyleştirilmesinden, topluluğun çözünmesinden ve her şeyden önemlisi dünyanın büyüsünün bozulmasından sorumlu olan burjuva sınai dünyanın bir eleştirisi" olan romantizm akımında (Michael Löwy'den aktaran Oğuz, 2011, s. 51) "endüstri öncesi, egzotik dinsel ve asli" yönlerden Doğu'ya bir öykünme vardır. Yani romantizmin gelişimi hızla büyüyen Alman sanayisine alternatif bir itici bir güç olduğu söylenebilir. Romantikler “Doğu'yu kendi kültürel, dinsel, tarihsel ve edebi bütünlüğü içerisinde kendi kurallarına göre, (Almanların da) bir tarihi olarak ve önemli bir ilgi sahası olarak" anlaşılması gerektiğini talep etmişlerdir (Mangold, 2004, s. 45). Bu bağlamda Hammer-Purgstall'ın Almanca konuşulan dünyada İslami dönem Fars edebiyatına ilginin uyanmasında ayrıcalıklı bir yeri vardır. Hammer-Purgstall'ın Doğu şiiri ve İran mistisizmi ilgisi 18. yüzyılın son dönemlerinde aydınlanmacı dünya görüşüne tepkinin bir parçası olarak değerlendirilebilir (Irwin, 2008, s. 156). Onu en çok etkileyen kişilerden biri de 1784 yılında Kalküta'da The Asiatic Society kurucusu İngiliz oryantalist-filolog ve sömürge danışmanı William Jones (1746-1794) ve Farsça çevirileri olmuştur. (Polaschegg, 2005, s. 149; Hammer-Purgstall, 1818, s. VI). Jones'un HammerPurgstall açısından bir diğer önemi ise yazdığı Farsça gramer kitabının İranlı şairlerden yaptığı alıntılardan meydana gelmesidir. Böylece Fars şiiri ve Sanskritçeyi Batı'ya tanıtan ve özellikle Hint-Avrupa teorisini ortaya koyan Jones, Hammer-Purgstall'ın yanısıra birçok Alman oryantalist ve romantiklere de ilham kaynağı olmuştur. Fars şiiri üzerine yaptığı

4 18. yüzyılın başlarında, Doğu hakkında oldukça coşkulu olan ve 1670 ve 1675 yılları arasında İstanbul'da Fransız elçiliğine bağlı olarak da çalışan Antoine Gallands'ın (1646-1715) Arap dönemi masalları koleksiyonu Bin Bir Gece Masalları çevirisi daha sonra bunların farklı Avrupa dillerine çevrilmesi Avrupa'da Doğu'ya edebi ilginin duyulmasında önemli bir yere sahiptir. Bunun yanısıra Gotthold Ephraim Lessing'in (1729-1781) 1779 yılında kaleme aldığı Nathan der Weise (Bilge Nathan) adlı eseri "üç İbrahimi dine gösterdiği toleransla Aydınlanmanın en güzel dramasıdır". 18. yüzyılın sonlarında ortaya çıkan bu çalışma günümüzde bile halen etkisini sürdürmektedir (Schimmel, 2012, s. 66-67; Irwin, 2008, s. 119-120). 
yoğun çalışmalar Jones'u "Avrupa edebiyatının bayatladığı ve klasik örneklerden özgürleşmesi gerektiği" sonucuna götürmüştür (Irwin, s. 126-127). Bu yönüyle Jones, daha sonra bahsedileceği gibi gazel formunu Alman şiirine dâhil eden Hammer-Purgstall, Goethe ve Rückert üzerinde önemli bir etki bırakmıştır.

Fars şiiri, Hintçe ve Sanskritçe çalışmaları alanında da İngilizlerden daha çok egemen olan bazı Alman aydınlar, Hint-Ari medeniyetinin Sami kültürüne kıyasla daha üstün olduğunu öne sürmüşlerdir. Bunlardan biri olan oryantalist-filolog ve yazar Friedrich von Schlegel (1772-1829) Über die Sprache und der Wiesheit der Inder/Hintlerin Dili ve Bilgeliği Üzerine (1808) adlı eserinde Sanskrit kökenli dillerin Sami dillerinden daha üstün olduğunu iddia etmiştir. Hintçe ve Sanskritçe meraklısı olan Kardeşi August Wilhelm Schlegel (17671845) ise "istisnasız her şeyin kaynağının Hindistan'da" olduğunu iddia etmiştir (Irwin, s. 160; Said, 1979, s. 98). Edward Said'e göre, "romantizmin en yüksek derecesini arayacağım yer Doğu'dur" diyen August Wilhelm von Schlegel'in aslında kastettiği şey Sakuntala, Zend-Avesta ve Upanişat metinleridir (Said, s. 98). İşte böyle bir edebi atmosferde yetişen Hammer-Purgstall, 1794 yılında arkadaşı Karl Borromäus Harrach (1761-1829) ile beraber Hâfız şiirlerini okumaya başlamıştır. Hâfız ile meşgalesi onun daha sonraki çevirilerinin ilk basamağı olmuştur (Baum, 2004, s. 4).

\section{Hammer-Purgstall’ı Ortaya Çıkaran Ruh ve Çevirileri}

1774 yılında Avusturya'nın Graz şehrinde doğan Hammer-Purgstall, annesinin ölümünün ardından 14 yaşında Kraliçe Maria Theresa'nın kurduğu ve Habsburg Hanedanlığı için Doğu dillerini bilen diplomat yetiştiren bir okul olan Kaiserlich-königliche Akademie für Orientalische Sprachen/Doğu Dilleri Imparatorluk ve Kraliyet Akademisi ne kayıt olmuştur. Burada dokuz yıl süren uzun bir eğitimin ardından Farsça, Arapça, Türkçe gibi Doğu dillerini öğrenen Hammer-Purgstall, Osmanlı topraklarına diplomat olarak gönderilerek farklı birimlerde görev almıştır (Gibson, 2015, s. 99). Uzun yıllar İstanbul'da görev yapan Hammer-Purgstall, burada Doğu yazmalarını ve klasik Fars edebiyatı alanında yazı Imış şerhleri inceleme imkânı bulmuştur. 1809-1818 yılları arasında dönemin baskın olan teolojik geleneğinden farklı olarak yayımladığı Fundgruben des Orients/ Doğunun Kaynakları adlı ilk dergi olma özelliği ile Almanca konuşulan dünyada bu alanın öncülerinden olmaya hak kazanmıştır. Motto olarak Bakara Suresi'nin; "Sag: Gottes ist Osten und Gottes ist der Westen; Er leitet wenn er will, den rechten Pfad/Doğu da Batı da Allah'ındır. Allah dilediği kimseyi doğru yola iletir" 142. ayetini kullanan dergi, içerik olarak "Doğu ile ilgili ne varsa" kapsamıştır (Avcı, 2018, s. 35). Kendi çevirilerini de bu dergide 
yayımlayan (Baum, 2004, s. 4) Hammer-Purgstall, bir taraftan oryantalizmin Alman üniversitelerinde baskın olan teoloji anlayışının aksine bilimselleşme ve filolojik gelenek inşasında bir kapı açarken diğer taraftan da edebi oryantalizme ilgi duyulmasında öncü olmuştur.

"Şiirin bir insanın tam olarak anlaşılması için bir temel" olduğuna inanan HammerPurgstall, özellikle "Doğu'nun şairlerini iyice incelemek ve daha sonra tarihe yönelmek istediğini" (Gibson, s. 101) belirterek edebi çevirilerden tarih araştırmalarına oryantalizmin farklı alanlarında oldukça önemli eserler bırakmıştır. 1809 yılında İran edebiyatında önemli bir yeri olan Hüsrev ve Şirin hikâyesini İstanbul ve Viyana kütüphanelerindeki yazmalardan faydalanarak iki cilt halinde Schirin, ein morgenlaendisches Gedicht nach morgenländischen Quellen/Şirin, Doğu kaynaklarına Göre Doğu Şiiri adıyla Almancaya kazandıran Hammer-Purgstall, çeviri metnini oluştururken Nizâmî-i Gencevî, Dihlevî , Âsaf Han, Abdullah Hatusi, Âhî ve Karamanî gibi Türkçe şerh ve Farsça nüshalarından faydalanmıştır (Hammer-Purgstall, 1809, s. XXI).

Oryantalistlerin yanısıra Alman romantik şairler de Doğu şiirine yakın ilgi duymuşlardır. Hammer-Purgstall Viyana'da Alman romantizminin öncülerinden olan August Wilhelm Schlegel ve Friedrich Schlegel (Schlegel kardeşler) ile tanışmıştır. Hammer-Purgstall'ın Şirin çevirisinden oldukça hoşlanan August Wilhelm Schlegel ise onunla edebi sohbetler ve tartışmalar yaparak daha fazla zaman geçirmiştir. Her ne kadar Alman romantizminden etkilense de daha çok erken dönem liberallerden olan Hammer-Purgstall genel anlamda Schlegel kardeşlerle çok uzun ve derin ilişki kurmamıştır (Baum, 2004, s. 8-9)5. Schirin adlı çevirisini yaptıktan üç yıl sonra 1812 yılında 14. yüzyıl İran şairlerinden Hâfız-ı Şirâzî'nin gazellerinden oluşan Divan eserini Almancaya çeviren Hammer-Purgstall (1812) önsözünde okurlarına genel anlamda Fars edebiyatının form içerik ve düşünsel yapısını tanıtmayı denemiştir. Hâfız çevirilerinde divan edebiyatı şairlerinden Sürûrî, Sûdî ve Şem'î'nin şerhlerinden faydalanan ve içerik olarak Hâfız'ın anlam çeşitliliği üzerinde duran Hammer-Purgstall, Fars şiirindeki anlam sembol ve ritmi korumaya gayret etmiş aynı zamanda Avrupa şiirinden farklılığına vurgu yapmıştır (Hammer-Purgstall, 1812, s. I-XLII). Onun Hâfız çevirileri Almanca konuşulan dünyada hem çağdaşı hem de ölümünden sonra bile birçok Alman oryantalist ve şairi etkilemiş İslami dönem Fars dili ve edebiyatı çalışmalarının önünü açmıştır (Schimmel, 1992, 4). Hammer-Purgstall ile aynı okuldan mezun olan ve 1807 yılından 1823 tarihine kadar İstanbul'da görev yapan Habsburglu

5 Friedrich Schlegel, 1809 yılında Hammer-Purgstall'ı ziyaret etmiş ve bir mektubunda ondan sevgili dostum diyerek bahsetmiştir (Baum, 2004, s. 8-9). 
diplomat Valentin von Huszár'ın (1788-1850) Mevlânâ Celâleddîn-i Rûmî'nin Meșnevî ya da Vinzenz Rosenzweig von Schwannau'nun (1791-1865) Câmî'den yaptığı Joseph und Suleicha/Yusuf ve Züleyha Almanca çevirisinde Hammer-Purgstall'ın destek ve etkisi vardır. $\mathrm{Bu}$ çalışmalar Hammer-Purgstall tarafından kendi dergisinde yayımlanmıştır (Gibson, 2015, 2. 117). Hammer-Purgstall ile Viyana'da aynı çevrede bulunan Schwannau, onun izinde üç ciltlik bir Hâfız çevirisini uzun yıllar sonra 1858 ve 1864 yılları arasında yayımlamıştır. Çalışmasına Hammer-Purgstall'dan farklı olarak Hâfız'ın orijinal Farsça gazellerini de ekleyen Schwannau, çevirilerinde hece vezni kullanmış ve teknik olarak Hâfız'ın gazel formuna sadık kalmayı denemiştir (Schwannau, 1858-64). Oldukça iyi derecede Farsça bilen Schwannau, Divan'ın tamamını çevirmiş ve gazelleri Almancalaştırma denemesinde yaptığı çevirileri Hammer-Purgstall ile kıyaslandığında içerik olarak Hâfız'a daha bağlı kalmıştır. Yani gazellerin çevirisinde onun hatalarına düşmemiştir (Wohlleben, 2004, s. 16). Schawannau ve Huszár örneğinde ve daha sonra birçok oryantalist ve şairde görüleceği gibi Hammer-Purgstall, Alman oryantalizmi içerisinde İslami dönem Fars edebiyatında literal bir ağ kurmuş ve ağın içeresinden oldukça zengin çeviriler doğmuştur. İki kültür arasındaki kültürel transferi sağlayan bu çeviriler Almanya'da Doğu'nun romantize edilmesinde bir aracı rol oynamışlardır.

Çocukluğundan beri Fars şiirine ilgi duyan Hammer-Purgstall, yaptığı edebi çevirilerin yanısıra yaşadığı dönemde oldukça yaygın olan tarzda farklı dil ve formda şiirler yazmıştır. Fars dilini Arapça ve Türkçeye kıyasla daha özel bir yere koyan Hammer-Purgstall'a göre sadece Arapça ve Farsça şaheserlerin taklidi olan Türk edebiyatı bu dillerden yapılan çevirilerle zenginleşmiştir. Fars edebiyatını içerik ve form olarak "bütün Doğu nâzımının çiçeği" olarak kabul eden Hammer-Purgstall, Fars şiir sanatının Arapça dize ölçüsünü alarak kendi şiir formuna adapte etmeyi başardığını iddia etmiştir (Hammer-Purgstall 1818, s. V). ${ }^{6}$ Hammer-Purgstall'ın Fars dili ve edebiyatına neden bu kadar yakın ilgi duyduğu sorusunun cevabını dönemin ruhunda aranmalıdır. Zira Hammer-Purgstall, 19. yüzyılın ilk yarısında şekillenen Hint-Avrupa düşüncesinin etkisinde filolojik olarak Farsçayı kardeş bir dil olarak değerlendirmiş (Hammer-Purgstall, 1812, s. VII) ve Germenleri "eski bir Farsi kavim" olarak betimleme yoluna gitmiştir. Ona göre yapılan ayrıntılı dil çalışmaları sonucu Farsça ve Almancanın akraba diller olduğu artık ortaya çıkmıştır. Fars edebiyatının Almanya'da ilgi uyandırması köken birliğinin yanısıra retorik ve poetik gelişimlerinde ortak bir kader birliği taşıyor olmalarından kaynaklanmaktadır (HammerPurgstall, 1818, s. VII).

6 Bu küçümseyici bakışına rağmen Türk edebiyatı ile ilgili bazı çalışmalar yapmaktan da geri kalmamıştır. Bkz. (Hammer-Purgstall, 1836-1838; Hammer-Purgstall, 1825). 
Hammer-Purgstall'ın Hâfız'dan yaptığı çeviriler ve diğer çeviri çalışmaları Alman oryantalistler arasında ciddi bir tartışmaya neden olmuştur. Özellikle çağdaşı oryantalistlerden Friedrich Heinrich von Diez (1794-1876) "baştan savma ve yüzeysel" bulduğu çevirilerini şiddetli bir şekilde eleştirmiştir (Galter, 2009, s. 459; Mangold, 2004, s. 47-51). 1811 yılında Keykâvus bin İskender'in Kabûsnâme eserini Farsçadan Almancaya çeviren Diez, (Gibson, 2015, s. 331) meslektaşı Hammer-Purgstall ile ciddi akademik tartışmalar ve çekişmeler yaşamıştır. Hammer-Purgstall gibi İstanbul'da diplomat olarak görev yapan Diez'in Farsça çevirileri oryantalist çevrelerce oldukça ilgi görse de HammerPurgstall kadar tanınmasına olanak sunmamıştır.

Hammer-Purgstall'ın Hâfız ve Fars edebiyatından yaptığı diğer çeviriler sıradan ve şiirsellikten uzaktır. Buna rağmen Almanca konuşulan dünyada Doğu'nun edebi anlamda Alman oryantalizminin bir parçasına dönüşmesinde onun Farsça, Türkçe ve Arapça gibi Doğu dillerinden Batı dillerine kazandırdığı edebi çevirilerin çok önemli bir etkisi vardır. Hammer-Purgstall, Alman oryantalizminde yarattığı en önemli etkilerden biri de şair, çevirmen ve dilbilimsel ve edebi dehası ile tanınan oryantalist, şair ve filolog olan Rückert'i yetiştirmiş olması ve kendinden sonraki çevirilere nerdeyse temel kaynak olmasıdır. Literal Doğu bilgisinin transferi bağlamında düşünüldüğünde Hammer-Purgstall, Schawannau, Rückert, Platen ve Goethe arasında literal bir ağdan bahsetmek yanlış olmayacaktır.

\section{Literal Ağ ve Poetik Bellek}

Hammer-Purgstall'ın Geschichte der schönen Redekünste Persiens/Fars Belâgati Tarihi eseri ve Hâfız çevirileri Rückert'in Fars şiirine olan ilgisinin temel dayanağı olmuştur. Hâfız'ı sadece Hammer-Purgstall'ın Almanca çevirileri üzerinden değil, bizatihi Farsça okuyan Rückert, 1818 yılında Hammer ile Viyana'da yoğun bir çalışma dönemi geçirmiştir (Höflechner \& Wagner, 2018, s. 8). İranlı şairlere "sınırsız bir coşkuyla" yaklaşan Rückert'in 1821 yılında yayımladığı ve yeni keşfettiği Hâfız'ın ruhunun hissedildiği, genel olarak Fars şiirinin etkisiyle ortaya çıkan Östliche Rosen/Doğu Gülleri adlı eseri Hammer-Purgstall'ın etkisiyle yazdığı şiirlerdir. Bu çalışmasında Mevlânâ'nın kırk dört gazelini Alman edebiyatına kazandırmıştır. Hammer'in Hâfız ve Fars edebiyatının diğer eserlerinden yaptığı çeviriler gazel formuna oldukça yabancı sıradan ve şiirsellikten uzaktır. Onun aksine Rückert, oryantalist şair ve çevirmen olarak Hâfız ve Mevlânâ gazellerini Almancalalaştırırken sıradan çevirilerden ziyade onun ruhunu ve formunu kendi şiirine yansıtmayı başarmıştır (Bobzin, 1989, s. 4; Shabrawy, 1974, s. 45). “Dillerin ve edebiyatın çeşitliliğinde insan ruhunun birliğini keşfetmeyi arzulayan" Rückert, Farsçadan çevirdiği 
gazelleri Alman şiir tonuna benzetmiştir. Hammer'den aldığı ruhla içerisinde "bilgeliğin" olmadığı bir çalışmadan uzak duran Rückert, söz sanatı, şiirsel ilham ve akıcılık ve tarihsel arka planı çevirilerin içine yerleştirerek aktarmayı başarmıştır. Farsça ve Almanca arasındaki tarihsel-karşılaştırmalı dilbilimin sonuçlarını dikkatli ve verimli bir şekilde işlemiştir (Mumm, 2013, s. 445-446). Hâfız'ın gazellerinde Rückert'i en çok etkileyen şey onun şiirine sinmiş olan "nihai kaderin anlaşılmazlığı, insanın evrenin bilmecesinde ustalaşamaması" gibi ifadeler olmuştur (Shabrawy, 1974, s. 45). Yani Fars edebiyatının mistik sûfî boyutu Rückert'in klasik Alman edebiyatından romantizme kaçışındaki içsel gerekçeler arasında sayılabilir.

Rückert'in gazelleri Almancalaştırma denemesini Mevlânâ çevirileri ve etkisinde görmek mümkündür. Rückert, böylece Alman dili ve şiir formunu zenginleştirmeyi amaçlamıştır (Avcl, 2018, s. 26). Bu ilgi Rückert'in 1819 yılında daha önce Hammer-Purgstall'ın çalışmalarıyla tanıştığı Mewlana Dschelaladdin Rumi adlı çalışmasıyla daha somut bir şekilde ortaya çıkmıştır (Rückert, 1819). Hammer-Purgstall'ın çevirideki yeteneğinin Rückert'in şiirsel dehası ile birleşmesi sonucu ortaya çıkan bu eser, Almanca konuşulan dünyaya Mevlânâ mistisizminin kapılarını açmıştır. Her ne kadar Rückert, Fars edebiyatını keşfinde Hammer'den oldukça etkilenmiş olsa da, Hammer'in şiirlerini arkadaşı Platen'a 1825 yılında yazdığı mektupta teknik açıdan ciddi bir şekilde eleştirmiştir (Höflechner \& Wagner, 2018, s. 132-133). Fars edebiyatına ilgisi yalnızca Hâfız ve Mevlânâ ile sınırlı kalmayan Rückert, Sa'dî'den birçok çeviri yapmış ve bunların bir kısmı ölümünden sonra basılmıştır. 1838 yılında Fars edebiyatının oldukça önemli bir eseri olan Firdevsî'nin Şehnâme adlı eserinin bir parçası olan Rüstem ile Sohrab destanını Rostem und Sohrab (1838) adıyla çeviren Rückert'in Bostan çevirisi ise ölümünün ardından ancak 1882'de (1882) basılabilmiştir. Edmund Alfred Bayer'in, Rückert'in Sa'dî'nin Divanı́ndan yaptığı çevirileri 1893 yılında (Rückert, 1893) onun bazı şiirlerini ise Saadis Politische Gedichte/Sa'dínin Siyasi Şiirleri adıyla daha sonra terekesinde bir araya getirerek 1894 yılında yayımlamıştır (Rückert, 1894). Ayrıca Bayer, 1894 'te Rückert'in terekesinde bulunan notlardan hareketle Şehnâme'yi de çevirmeyi denemiş fakat tamamlayamamıştır. Yarısına kadar çevirebildiği ve terekesinde bulunan bölümler ölümünün ardından yine Bayer tarafından birleştirerek üç cilt halinde kitaplaştırılmıştır (Rückert, 1890-1895). Onun Fars şiirinde Hammer'den ne kadar etkilendiği ve ona nasıl bir değer biçtiği An J. von Hammer adli şiirinde açıkça görülebilir.

Den Dolmetschen der Pforte dort im hochtürmenden Wiene,

Der, so hat mir Hafis gesagt, löst mit glücklicher Schnelle

Jedes Rätsel aus Osten, das schwierig anderen schiene 


\section{Sarayın tercümanı orada yüksek kuleli Viyana'da}

diğerlerine zor görünen Doğu'daki her bilmeceyi daha mutlu bir hızla çözer bunu bana Hâfız söyledi (Rückert, 1868, s. 254).

Rückert, yaşadığı dönemde filoloji çalışmalarında baskın olan Hint-Avrupa teorisinin etkisiyle Hammer-Purgstall gibi Farsça ve Almancanın akraba olduğunu iddia etmiştir. "Özellikle zamanımızın son araştırmalarına bakarsanız, Farsça ve Almanca arasında bir ilişki olduğunun şüphe götürmediğine şahit olursunuz" ifadesi onun bu teoriden etkilendiğine somut bir örnektir (Radjaie, 1998, s. 41). Kendisi de zaten (Franz Bopp'un öğrencisi olan) bu teorinin pratisyenlerinden biri olarak Erlangen Üniversitesi'nde 1826 ile 1841 yılları arasında Hint-Avrupa teorisini temsil etmiştir. Hint-Avrupa (Indogermanistik) teorisi Avrupa dillerinin çoğunluğunun ve bazı Asya dillerinin genetik olarak birbirleriyle ilişkili olduğu görüşüne ve ortak bir temel dilden çıktığını kabul etmeye dayanmaktadır?. Hint-Avrupa dil ailesinin Hint-İran kolunun İrani diller sınıfına dâhil olan Fars diline Almancanın akraba bir dili olarak duyulan etimolojik ilgi Fars edebiyatı çalışmalarını teşvik etmiş olsa da yukarıda da vurgulandığı gibi onu Sanskritçenin gölgesinden kurtaramamıştır. 19. yüzyılda Fars edebiyatını Alman dili ile buluşturan en üretken ve çalışkan çevirmenlerinden biri olan Rückert, İslami dönem Fars şiirini ve dolaylı olarak kültürünü Almanca konuşulan dünyaya transfer etmiştir. Rückert, Fars şiiri ile tanışmadan önce form olarak önce iki dörtlü ve iki üç mısradan meydana gelen Sonettler yazmıştır. Gazel formunu Almancaya uyarlama onun şiirini çeşitlendirerek zenginleştirmiş̧tir.

Ölümünden sonra 1874 ylında onun daha önce Fundgruben des Orients dergisinde çevirilerini yayımladığı Gāzi-'d-Dīn Ḥaidar'ın Haft Qulzum adlı eseri Wilhelm Pertsch tarafından Grammatik Poetik und Rhetorik der Perser/Farsların Gramer, Poetika ve Retorikası adıyla kitaplaştırılmıştır (Rückert, 1874). Rückert'in yanısıra onun yardımıyla Gazel formuna aşina olan August von Platen da Fars şiirine oldukça ilgi duymuş ve Hâfı'dan etkilenerek gazeller yazmıştır. Rückert'ten bağımsız ve ondan daha önce Farsça öğrenmeye başlayan Platen ve Rückert mektuplaşmaları Hâfız şiirinin Almanca'ya uyarlanma çabalarına örnek olarak verilebilir. Platen, sadece Fars şiirinden etkilenerek Almanca gazeller yazmamıştır. Bilakis Hâfız'dan çeviriler yapmıştır (Bobzin, 1989, s. 4).

Hammer-Purgstall'ın çevirileri Rückert'in aksine Farsça bilmeyen Goethe'nin Der west östlicher Diwan/Doğu Batı Divanı eserine ilham kaynağı olmuştur. Bunun yanısıra Hammer- 
Purgstall'ın yukarıda bahsedilen Geschichte der schönen Redekünste Persiens adlı İran şiiri ve şairleri anlattığı eseri ise Goethe'nin yukarıda bahsedilen Divan eserinin içinde bir parça olan Noten und Abhandlungen adlı çalışmasına da kaynak olmuştur (Bruijn, 2003; Solbrig, 1970, s. 117). Goethe'nin kendi ifadesi ile Hammer-Purgstall'dan nasıl etkilendiği alıntıdan anlaşılabilir: "Hâfız'ın şiirleri, Hammer'in tercümesiyle, geçen yıl elime geçti (1814). Bundan önce, şurada burada, dergilerde çevrilmiş bazı münferit şiirler, bana, bu parlak şairi pek duyurmamıştı. ...Almanca tercümeleri, önümde duruyor" (Özgü, 1952, s. 89-90). Her ne kadar Hammer-Purgstall Goethe'nin Doğu şiirine daha özelde Fars edebiyatına ilgisinde önemli bir rol oynasa da Diez, Goethe'yi oldukça fazla etkilemiştir (Gibson, 2015, s. 331; Diez ve Goethe arasındaki etkileşime ışık tutacak en kapsamlı araştırma için bkz. Mommsen, 1961).

İngilizler Kalküta'da Doğu'yu keşfederken Alman aydınlarda bu süreç biraz daha farklı işlemiştir. Onlar için bu dünyanın önce düşünsel bir keşfi gerekiyordu. Bu bağlamda Alman şair, filozof ve oryantalist Johann Gottfried Herder (1744-1803), başka bir milletin yaşamını inceleyenlere öncelikle o kültürü "kendi kardeşlerininki olarak tanımaları" tavsiyesinde bulunmuştur (Schimmel, 2012, s. 68). Doğu dilleri ve edebiyatına yakın ilgi duyan Herder, Hammer-Purgstall'ın çalışmalarına ilgi duymuştur. 1803 yılında ölen Herder, HammerPurgstall'ın çevirilerinden etkilenmiş olsa da Herder'in Fars şiiri ile ilk tanışması onun çalışmaları aracılığıyla olmamıştır. Herder, 1769 yılında Nantes/Fransa'da bulunduğu dört aylık süre zarfında Doğu şiiri çevirilerini okumuş ve Sa'dî'nin farklı Avrupa dillerine çevrilmiş olan Gülistan eserinden oldukça etkilenmiştir (Schimmel, 1995, s. 27). Bu ilginin bir meyvesi olarak Herder'in Gülistan'ın bazı öykü ve şiirlerine uyarladığı Blumen aus morgenlaendischen Dichtern/Doğu Şiirinden Çiçekler adlı kitabı ölümünün ardından 1807 yılında yayımlanmıştır (Shamel, 2007, s. 149). Bu çalışmasının yanısıra Briefe zu Beförderung der Humanität/Insanlığın Yükselişi Için Mektuplar adlı çalışmasında kullandığı kafiye usulünde Fars şiiri etkisini görmek mümkündür. Fakat sonraki şiirlerinde daha çok Arap şiiri etkisi göze çarpar. Zaman içerisinde Hammer-Purgstall'ın çevirilerini yakından takip eden Herder'in 1803 yılında dergisi Adrastea'da onun çalışmalarına nasıl değer verdiği tasvir etmek için yeterlidir.

Doğu ve güney dünyasının iki dayanağını Fars ve Arap dillerini onları onun elinde hilenin ve baskının değil refahın ve bereketin aracı yap. Biz Avrupa'da da bu dillerle oynamak istemiyoruz. Onlardan ve onlarla öğrenmek istiyoruz. Hâfız'ın şarkılarından bizde yeteri kadar var, Sa'dî bize öğretici oldu. Çok dilli ve yetenekli genç Hammer'den Şark'la ilgili beklentilerimiz gerçekleşiyor (Schimmel, 2012, s. 70-72). 


\section{Sonuç}

19. yüzyılda Alman bilim dünyasında Doğu araştırmalarında gelenek haline gelen ve oldukça etkili bir metodoloji olan filoloji, karşılaştırmalı dil çalışmalarının önünü açarak farklı Doğu kültürlerinin incelenmesini sağlamıştır. Arap dili ve edebiyatından yapılan çevirilerin yanısıra Sanskritçe ve Farsça üzerine de önemli çalışmalar yapılmıştır. Romantizm ve HintAvrupa düşüncesinden de etkilenen Hammer-Purgstall, İslami dönem Fars edebiyatına yakın bir ilgi duymuş ve Alman edebi oryantalizminde kurucu bir rol üstlenerek çevirileri ile içeresinden oldukça zengin malzemeler çıkan literal bir ağ kurmuştur. Hammer-Purgstall'ın İslami dönem Fars edebiyatından Almancaya yaptığı çeviriler, sadece birbirinden farklı iki kültür arasında bir transfer rolü icra etmemiş, aynı zamanda birbirlerine zaman ve mekân olarak da oldukça uzak olan iki medeniyetin poetik belleği arasında bir köprü vazifesi görmüştür. Hammer-Purgstall ile Fars şiiri üzerine mütalaa eden ve zaman içerisinde Fars şiirinin estetik, ahenk ve formundan etkilenen Rückert örneğinde görüldüğü gibi mistisizmin ve döneme hâkim olan romantik anlayışın yanısıra Alman şiirini zenginleştirmek amacıyla da Fars edebiyatından çeviriler yapılmıştır. Alman edebiyatının en büyük şairlerinden biri olan Goethe'nin Hammer-Purgstall aracılığı ile Fars şiirlerinin çeviri ve formları ile tanışması ve oradan aldığı ruhu kendi şiirine yansıtması Almanca konuşulan dünyada Fars diline ve İran medeniyetine ilginin oluşmasında ciddi bir rol oynamıştır.

Finansal Destek: Yazar bu çalışma için finansal destek almamıştır.

\section{Kaynakça}

Avcı, R. (2018). Alman Oryantalizmi: Carl Heinrich Becker ve Martin Hartmann Örneğinde Osmanlı Toplum ve Siyaset Söylemi (Doktora tezi). Mardin Artuklu Üniversitesi Sosyal Bilimler Enstitüsü. Mardin.

Baum, W. (2004). Josef von Hammer Purgstall. F. Schipper (Ed.). Zwischen Euphrat und Tigris. Österreichische Forschungen zum Alten Orient. (s. 3-18). Wien: Lit Verlag.

Behzad, F. (1970). Adam Olearius Persianischer Rosenthal Untersuchungen zur Übersetzung von Saadis 'Golestan' im 17. Jahrhundert. Göttingen : Vandenhoeck \& Ruprecht.

Bobzin, H. (1989). Hafisische Vierzeiler in Übertragungen von Friedrich Rückert. Spektrum Iran. 2(4), 3-26.

Bruijn, J. T. (2003). Joseph Fresherr von Hammer-Purgstall. Encyclopaedia Iranica: http://www.iranicaonline.org/ articles/hammer-purgstall (Erişim tarihi: 30.07.2019).

Bulut, Y. (2004). Oryantalizm Kısa Tarihi. İstanbul: Küre Yayınları.

Gallien, C. (2018). Orientalist Pococke:Brockering Across Borders, Disciplines and Genders . R. Mankin (Ed.). The Internationalization of Intellectual Exchange in a Globalizing Europe, 1636-1780 Transits: Literature, Thought \& Culture, 1650-1850 (s. 1-30). Lewisburg: Bucknell University Press. 
Galter, H. D. (2009). Joseph von Hammer-Purgstall und die Anfänge der Orientalistik. K. Acham (Ed.). Kunst und Geisteswissenschaften aus Graz. Werk und Wirken überregional bedeutsamer Künstler und Gelehrter: vom 15. Jahrhundert bis zur Jahrtausendwende. (s. 457-470). Köln-Wien-Weimar: Böhlau Verlag.

Gibson, L. J. (2015). Changing States:Ottoman Sufism, Orientalism, and German Politics, 1770-1825 (Doktora tezi). University of California, Oakland-Kalifornien.

Graf, K. F. (1846). Moslicheddin Sadi's Rosengarten. Leipzig: F. A. Brockhaus.

Hammer-Purgstall, J. v. (1809). Schirin : ein persisches romantisches Gedicht nach morgenländischen Quellen. Leipzig: Fleischer.

Hammer-Purgstall, J. v. (1812). Der diwan von Mohammed Schemseddin Hafis. Aus dem Persischen zum erstenmal ganz ubersetzt von Joseph v. Hammer. Stuttgart-Tübingen: Verlag der J G Cotta`schen Buchhandlung.

Hammer-Purgstall, J. v. (1818). Geschichte der schönen persischen Redekünste. Wien: Ben Heubner verlag. Hammer-Purgstall, J. v. (1825). Baki's, des grössten türkischen Lyrikers, Diwan. Wien: Im Verlage der C.F. Beck'schen Buchhandlung.

Hammer-Purgstall, J. v. (1836-1838). Geschichte der Osmanischen Dichtkunst bis auf unsere Zeit. Mit einer Blüthenlese aus zweitausend zweihundert Dichtern (Cilt IV Cilt). Pest.

Hammer-Purgstall, J. v. (1850). Literaturgeschichte der Araber: von ihrem Beginne bis zu Ende d. 12. Jhs. d. Hidschret (Cilt 7 Bände). Wien: Verlag Kaiserl Königl Hof- Und Staatsdruckerei.

Hammer-Purgstall, J. v. (1837). Geschichte der osmanischen Dichtkunst bis auf unsere Zeit mit einer Blüthenlese aus zweytausend, zweyhundert Dichtern. Pesth: conrad adolphs Hartleben's Verlag.

Herzog, C. (2010). Almanca Konuşulan Ülkelerde Türkiyat ve Şarkiyat Çalışmalarının Gelişimi Üzerine Notlar. Türkiye Araştırmaları Literatür Dergisi, C. 8 S. 15, 77-148.

Höflechner, W., \& Wagner, A. (2018). Josef von Hammer Purgstall: Briefe, Erinnerungen, Materialien. Graz: Akademische Druck- u. Verlagsanstalt.

Irwin, R. (2008). Oryantalistler ve Düşmanları. çev. B. Tırnakcı, İstanbul: Yapı Kredi Yayınları.

Ismatillaeva, D. (2012). Das Thema des Orients in der deutschen Literatur vornehmlich des 18. und 19. Jahrhunderts. N. T. Kordula Schulze (Ed.) Usbekisch-deutsche Studien IV Kontakte: Sprache, Literatur, Kultur, Didaktik(s. 177-183). Berlin: LIT Verlag.

Lewis, F. (2001). Golestān-e Sa'di. Encyclopædia Iranica : http://www.iranicaonline.org/articles/golestan-e-sadi (Erişim tarihi: 08.03.2019).

Mangold, S. (2004). Eine weltbürgerliche Wissenschaft: Die deutsche Orientalistik im 19. Jahrhundert. Stuttgart: Franz Steiner Verlag.

Mommsen, K. (1961). Goethe und Diez. Berlin : Akademie-Verlag.

Mumm, P. A. (2013). Friedrich Rückerts Bostan-Notizen und ihr sprachwissenschaftlicher Hintergrund. J. R. A. Jörn Steinberg. (Ed.). Friedrich Rückert: Saadi's Bostan. Aus dem Persischen übersetzt von Friedrich Rückert Werke der Jahre 1850-1851 (s. 445-459). Göttingen: Wallstein Verlag.

Ochsenbach, F. (1636). Gulistan, das ist, Königlicher Rosengarten. Tübingen. 
Oğuz, M. C. (2011). Romantizm ve Carl Schmitt'de Desizyonizm Fikri Hilal Onur İnce. (Ed.). Günümüzde Yeni Siyasal Yaklaşımlar (s. 49-91). İstanbul: Doğu Batı Yayınları.

Olearius, A. (1696). Der Persianische Rosenthal : In welchem viel lustige und angenehme Historien/ scharffsinnige Reden/ nützliche Lehr- und Grund-Regeln/Sententzen und Sprüche enthalten. Hamburg: Hertel.

Özgü, M. ( 1952). Goethe ve Hafız. Ankara: Türk Tarih Kurumu Basımevi.

Polaschegg, A. (2005). Der andere Orientalismus. Regeln deutsch-morgenländischer Imagination im 19. Jahrhundert. Berlin-New York: de Gruyter.

Radjaie, A. (1998). Das profan-mystische Ghasel des Hafis in Rückerts Übersetzung und in Rückerts Übersetzung und in Goethes Divan. Würzburg: Ergon Verlag.

Radjaie, A. (2018). Rumi-Rezeption bei Goethe, Rückert und Schimmel. Ed. A. Radjaie-H. R. Yousefi. Jalal ad-Din Rumi, Grundbegriffe seines Denkens. Nordhausen: Bautz Verlag, 134-152.

Rifat, M. (2004). Çeviriyi Düşünenler. M. Rifat (Ed.). Çeviri Seçkisi l: Çeviriyi Düşünenler. (s. 9-15). İstanbul: Sel Yayıncılık. Rückert, F. (1819). Mewlana Dschelaladdin Rumi.

Rückert, F. (1838). Rostem und Sohrab. Erlangen: Theodor Bläsing.

Rückert, F. (1868). Friedrich Rückerts Gesammelte poetische Werke. Frankfurt am Main : J. D. Sauerländer's Verlag.

Rückert, F. (1874). Grammatik, Poetik und Rhetorik der Perser : nach dem siebenten Bande des Heft Ḱolzum. Gotha: Friedrich Andreas Perthes.

Rückert, F. (1882). Saadi's Bostan aus dem Persischen übersetzt von Friedrich Rückert. Leipzig : Hirzel Verlag.

Rückert, F. (1890 - 1895). Firdosi's Königsbuch (Schahname). C. I-III. Berlin : Georg Reimer.

Rückert, F. (1893). Aus Saadis Diwan. E. A. Bayer (Haz.). Berlin: Hans Lüstenöder.

Rückert, F. (1894). Saadis Politische Gedichte. Berlin: Mayer und Müller.

Said, E. (1979). Orientalism. New York: Vintage Books.

Schimmel, A. M. (1995). Johann Gottfried Herder und die persische Kultur. Spektrum Iran: Zeitschrift für islamischiranische Kultur, 8. Jahrgang Heft 3, 25-38.

Schimmel, A. M. (2012). Doğu Batı Yakınlaşmaları: Avrupa'nın İslam Dünyası ile Karşılaşması. Çev. H. Ağuiçenoğlu. İstanbul: Avesta.

Schimmel, A. M. (1992). A Two-Colored Brocade: The Imagery of Persian Poetry. Chapel Hill-London: University of North Carolina Press.

Schmitt, R. (2001). Iranian studies in German: Pre-Islamic period. Encyclopædia Iranica. http://www.iranicaonline. org/articles/germany-iii (Erişim tarihi: 10 17, 2019).

Schwannau, V. R. (1824). Joseph und Suleicha: historisch-romantisches Gedicht; aus dem Persischen des Mewlana Abdurrahman Dschami. Wien: Kaiserlich Königliche Hof- und Privatdruckerei.

Schwannau, V. R. (1858). Der Diwan des grossen lyrischen Dichters Hafis. Wien: Kaiserlich Königliche Hof- und Privatdruckerei.

Schwannau, V. R. (1858-64). Der Diwan des großen lyrischen Dichters Hafis. Wien: Druck und Verlag der K. K. Hofund Staatsdruckerei. 
Shabrawy, C. B. (1974). Arabic Forms and Themes in nineteenth Century German and French Poetry: Rückert, Platen, Hugo, Lamartine, Gautier (Doktora tezi). University of Illinois at Urbana-Champaign, Urbana-Champaign.

Shamel, S. (2007). Goethe and Hafiz: Poetry and History in the West-östlicher Divan (Doktora tezi). Standford University, Stanford.

Solbrig, I. H. (1970). Über die Blumen- und Früchtesprache der Hareme. Publications of the English Goethe Society. 40:1, 117-122.

Warnero, L. (1644). Proverbiorum et Sententiarum Persicarum centuria. Leiden: Lugduni Batavarum.

Wohlleben, J. (2004). Die Ghaselen des Hafiz: Neu in deutsche Prosa übersetzt. Würzburg: Königshausen-Neumann. https://www.indogermanistik.phil.fau.de/studium/beschreibung-des-faches/ (Erişim tarihi: 26. 09. 2019). 